\title{
El naturismo como proyecto de reforma de los estilos de vida en Albano Rosell
}

Sebastián Stavisky*

\section{Introducción}

El 15 de septiembre de 1923, el periódico necochense Nuestra Tribuna publicó una colaboración internacional escrita desde Barcelona por la célebre militante anarquista Federica Montseny.' La autora comenzó su artículo manifestando sentirse obligada a tratar el asunto que le concernía dada la importancia que éste había adquirido en el último tiempo. El tema en cuestión era el naturismo y, particularmente, el problema de la práctica de una conducta de vida cuyo enorme potencial había sido limitado a la cura y prevención de enfermedades para las que la medicina diplomada se había mostrado incompetente. Para Montseny, la crítica del naturismo a la civilización y su deseo de retorno a la naturaleza no podía restringirse al afán de recobrar la salud perdida. Si en efecto buscaba alcanzar sus objetivos, el naturismo debía ser mucho más que una simple alternativa médica. La respuesta que entonces encontró al problema de la inconsistencia del naturismo fue la previsible para casi cualquier militante que abrazara la doctrina libertaria en las primeras décadas del siglo XX: "[El naturismo] ha de ser anarquista, porque sólo en la anarquía, en la verdadera libertad, será posible poner en práctica sus propósitos." ${ }^{2}$

Para la época en que Nuestra Tribuna publicó la colaboración de Montseny, varios militantes anarquistas de la península ibérica, del Río de la Plata y de otras regiones del mundo habían comenzado a experimentar con las potenciales virtudes de la medicina natural. Es posible suponer -como sugiere Josep Roselló- que dicho fenómeno haya sido motivado por el encuentro con una serie de principios ideológicos afines a las ideas libertarias de una naturaleza armónica y bondadosa a la que la civilización había venido a corromper con su orden

* Instituto de Investigaciones Gino Germani - Universidad de Buenos Aires. Consejo Nacional de Investigaciones Científicas y Técnicas.

1 Este artículo es fruto de un trabajo de archivo realizado durante una estancia de investigación en Barcelona, parcialmente financiada a través de un subsidio de la Facultad de Ciencias Sociales de la UBA. Agradezco enormemente al profesor Eduard Masjun Bracons, quien me dirigió y acompañó en el proceso de relevamiento de información.

2 Federica Montseny, "El Naturismo", en Nuestra Tribuna, año 2, n 25 , Necochea, 15 de septiembre de 1923, p. 2 artificial. ${ }^{3}$ Sin embargo, la difusión en la prensa anarquista de métodos naturistas del cuidado de la salud no siempre fue bien recibida por el conjunto del movimiento libertario. En ocasiones, se produjeron fuertes debates en torno a los presuntos beneficios del ensayo con técnicas curativas a distancia de la ciencia médica, y la utilización de argumentos fundados sobre el mito de una naturaleza sacralizada no era exclusiva de quienes se oponían de manera irrestricta al ejercicio de la ciencia médica. ${ }^{4}$ Así, aunque resulte prudente no pasarlo por alto, el hecho de que el anarquismo y el naturismo compartieran unos determinados presupuestos ideológicos no explica por qué ciertos militantes libertarios tomaron la decisión de ensayar con prácticas de la medicina natural, tampoco de qué manera lo hicieron ni cómo es que comprendieron este conjunto heterogéneo de saberes profanos de la salud.

Revisando las publicaciones de referentes naturistas y de anarquistas practicantes del naturismo de principios del siglo $X X$, se encuentra que -más allá de ciertos acuerdos generales en torno a un conjunto difuso de ideas- las preocupaciones que animaban a unos y otros eran bien distintas. Mientras las páginas de las primeras están en gran parte ocupadas por largas disquisiciones acerca del modo en que debieran tratarse las diferentes enfermedades, la correcta aplicación de los diversos métodos terapéuticos, los beneficios curativos de los distintos elementos de la naturaleza; en las segundas, el naturismo es, más bien, contemplado como un modo de conducta ética, un

3 Josep Roselló, La vuelta a la naturaleza. El pensamiento naturista hispano (1890-2000): naturismo libertario, trofología, vegetarismo naturista, vegetarismo social y librecultura, Barcelona, Virus Editorial, 2003 , p. 137. Respecto a las ideas sobre la naturaleza en el anarquismo español (y, podríamos decir, de habla hispana), los trabajos de Álvarez Junco y Lily Litvak continúan siendo referencias ineludibles. José Álvarez Junco, "La idea de la naturaleza", en La ideología política del anarquismo español (1868-1910), Madrid, Siglo XXI de España Editores, 1976, pp. 43-62; Lily Litvak, "La naturaleza", en Musa libertaria. Arte, literatura y vida cultural del anarquismo español, Barcelona, Antoni Bosch, 1981, pp. 1-28.

4 Sobre uno de estos debates en el anarquismo de Buenos Aires, Sebastián Stavisky, "Médicos de sí mismos. Medicina naturista, revolución social y éxodo de la ciudad en el anarquismo de Buenos Aires a comienzos del siglo XX", en Ecopolítica, n 16, 2016, pp. 2-25. También Kirwin Shaffer, en su estudio sobre la cultura anarquista en Cuba, refiere a una de estas controversias entre anarquistas y anarco-naturistas. Kirwin Shaffer, Anarchist Cuba: Countercultural Politics in the Early Twentieth Century, Oakland, PM Press, 2019, pp. 129-131. 
ideal de vida, un proyecto de reforma tanto individual como social. De esta manera, considero que si hubo militantes libertarios que adoptaron para sí métodos naturistas del cuidado de la salud, fue porque percibieron en éstos algo más que una mera afinidad ideológica, algo más, también, que la efectividad de un simple compendio terapéutico. En términos generales, los anarquistas que se volcaron al naturismo lo hicieron con la ilusión de encontrar en él un modo de conducta ética a través del cual avanzar en un proyecto de reforma de sus estilos de vida, una manera - podríamos decir - de comenzar a vivir en el presente de forma cuanto menos similar a como soñaban hacerlo en el futuro. "Ello es lógico y hasta necesario —argumentaba Montseny en su artículo-, ya que el naturismo aclara un punto luminoso de la humanidad del porvenir: la vida, bella y libremente vivida." 5

Uno de los militantes anarquistas que dedicó mayores esfuerzos a difundir el naturismo como un estilo de vida alternativo a los modos de organización de la sociedad de su tiempo fue Albano Rosell y Llongueras. A través de su participación, durante las primeras décadas del siglo $\mathrm{XX}$, en distintos proyectos revolucionarios y de reforma tanto en España como en el Río de la Plata, buscó enlazar sus ideas libertarias a una concepción del naturismo como proyecto de transformación tanto individual como social. Compartida por otros compañeros de ideas, esta concepción partía de una crítica a los usos exclusivamente terapéuticos y comerciales de la medicina natural que por entonces hacían muchos de los centros y consultorios que ofrecían sus servicios curativos en ambas regiones en las que residió. Sin embargo, también es preciso señalar que lo que podríamos llamar un naturismo libertario cobra sentido no sólo en contraste con los modos de ejercer tales formas alternativas de la medicina en el contexto más inmediato de su desarrollo. Considero que es necesario comprenderlo al interior de una historia dentro de la cual varios de quienes adoptaron métodos naturales de curación, antes de que militantes anarquistas percibieran en ellos —como decía Montseny - "un punto luminoso de la humanidad del porvenir", lo hicieron ya con la convicción de poder alcanzar, por su intermedio, un cambio en las formas sociales de vida.

A partir de estas consideraciones, en el presente artículo me propongo, en una primera parte, trazar un breve recorrido de la historia de la medicina naturista que permita echar luz sobre algunas de las distintas formas en que la misma fue practicada y difundida entre mediados del siglo XIX y comienzos del XX en

5 Federica Montseny, op. cit., p. 2. Esta hipótesis tal vez permita comprender por qué fueron los anarquistas de tendencia individualista, renuentes no sólo a su participación en organizaciones estables sino también a la espera de la revolución para comenzar a ensayar una transformación de sus estilos de vida, quienes mayormente se volcaron a la práctica del naturismo. Volveré sobre este tema hacia el final del artículo. Cfr. Sebastián Stavisky, "Manuel Costa-Iscar y el anarquismo individualista en Buenos Aires", en Izquierdas, n 49, julio 2020, pp. 996-1017.
Europa. Buscaré dar cuenta, por un lado, de ciertas experiencias que, previas a la emergencia del anarquismo, ya habían empezado a ensayar métodos naturistas del cuidado de la salud como parte de un proyecto más amplio de transformación; por otro, de las vías por las cuales tales métodos comenzaron a ser difundidos en España, país en el que Rosell se informó de su existencia y los adoptó para sí. En una segunda parte, a partir del análisis documental de los escritos de este último, indagaré en las críticas que, desde una perspectiva anarquista, Rosell expresó a los usos exclusivamente terapéuticos y comerciales de la medicina natural. Posteriormente, recompondré algunos de los puntos centrales de su concepción de naturismo integral como proyecto de reforma de los estilos de vida en respuesta, entre otras cuestiones, a los cambios producidos en ciertos hábitos de conducta por los desarrollos técnicos de la sociedad moderna. De esta manera, el artículo da cuenta de algunos de los elementos que permitan comprender las relaciones de tensión, debate y afinidad producidas hacia inicios del siglo XX entre el anarquismo y la medicina naturista.

\section{Inicios de la medicina naturista}

Las primeras experiencias naturistas del cuidado de la salud surgieron en el contexto de emergencia de un conjunto heterogéneo de medicinas alternativas que se produjo en Europa y Norteamérica a lo largo del siglo XIX. Varios de los trabajos dedicados a reconstruir la historia de estas prácticas coinciden en que su despliegue fue resultado, entre otros factores, de la marginación de ciertos saberes de la salud —muchos de ellos de raigambre popular, imbuidos de concepciones animistas y/o enraizados en antiguos postulados hipocráticos- que acompañó al desarrollo de la medicina experimental junto a los procesos de profesionalización y regulación de la práctica médica. ${ }^{6}$ De esta manera, el historiador británico Roy Porter afirma que sería imprudente calificar de alternativas a las prácticas no ortodoxas de la medicina previas al 1800 , en tanto las fronteras que las separaban de la medicina regular eran mucho más porosas de lo que, paulatinamente, luego comenzarían a ser. ${ }^{7}$

Dos de las regiones tal vez más prolíficas en la creación y difusión de estas nuevas disciplinas fueron, por un lado, los Estados Unidos, donde surgieron, entre otras, la herboristería thomsoniana, el movimiento de reforma nutricional liderado por Sylvester Graham (cuyo pan de harina integral tendría gran

6 William F. Bynum y Roy Porter (ed.), Medical Fringe and Medical Orthodoxy, 1750-1850, Londres y Wolfeboro, Croom Helm, 1987; Roger Cooter (ed.), Studies in the History of Alternative Medicine, Londres, Palgrave Macmillan, 1988; Willem de Blécourt y Cornerlie Usborne, "Situating 'Alternative Medicine' in the Modern Period", en Medical History, $n^{\circ} 43,1999$, pp. 283-285.

7 Roy Porter, "Before the Fringe: 'Quackery' and the Eighteenth-Century Medical Market", en Roger Cooter (ed.), op. cit., pp. 1-27. 
aceptación entre los naturistas), la osteopatía fundada por Andrew Taylor Still y la quiropráctica de David Daniel Palmer. ${ }^{8}$ Por otro lado, en la región del centro de Europa, particularmente en Austria y Alemania, surgieron la homeopatía de la mano de Samuel Hahnemann, el mesmerismo o hipnosis animal de Franz Mesmer, la hidropatía (también conocida como hidroterapia) de Vincent Priessnitz y Sebastian Kneipp y la nueva ciencia de curar de Louis Kuhne - los tres últimos parte de los más importantes precursores y referentes de la medicina naturista-.

Cada una de estas corrientes alternativas del cuidado de la salud mantuvo diversos tipos de relaciones con las formas de ejercicio de la medicina reconocidas por las distintas instancias de regulación o, más sencillamente — como se le solía llamar en las publicaciones naturistas-, con la medicina oficial. ${ }^{9}$ Aunque sus métodos resultaron muchas veces rechazados y denostados, también en ocasiones fueron aceptados, promovidos y hasta incorporados a los compendios terapéuticos de los médicos diplomados de distintos países. Asimismo, el tipo de relación que entablaron con esas corrientes alternativas quienes las practicaron fue también variado. Mientras algunas personas las adoptaron en reemplazo de la presunta ineficacia de las técnicas recomendadas por expertos, otras las asumieron de manera complementaria; mientras hubo quienes recurrieron a ellas sólo en momentos críticos de sus trayectorias biográficas, otros las siguieron de manera escrupulosa como forma de regimentación de sus conductas. Anticipando la proliferación de dietéticas, comercios de productos saludables y consultorios de terapias alternativas de las últimas décadas, algunos encontraron en las prácticas no ortodoxas de la medicina una posible veta comercial; otros, desde una perspectiva filantrópica, las difundieron entre los trabajadores como un método para garantizarles una mejora de sus condiciones de existencia en reemplazo de costumbres consideradas perniciosas tanto para su salud como para los niveles de productividad de la mano de obra. Finalmente, hubo quienes, enlazándolas a una crítica al orden social, las comprendieron como una posible respuesta a los cambios producidos por los desarrollos tecnocientíficos. ${ }^{10}$

8 James C. Whorton, Nature Cures. The History of Alternative Medicine in America, Nueva York, Oxford University Press, 2002.

9 Sobre la noción de medicina oficial", Matthew Ramsey refiere que, sin dejar de tratarse de una categoría dinámica y, por tanto, susceptible de revisión, "cada sociedad occidental, con algunas diferencias en el tiempo, llegó a reconocer lo que a mediados del siglo XIX se llamó la médecine oficielle en Francia —aproximadamente, la medicina de los médicos, la ciencia y el gobierno". Matthew Ramsey, "Alternative Medicine in Modern France", en Medical History, n 43, 1999, pp. 286-322, pp. 289-290. Esta traducción, así como la de otros fragmentos de trabajos referidos en idioma extranjero, me pertenece.

10 De esta diversidad de tipos de relaciones entabladas con un universo heterogéneo de prácticas de la salud se desprende el debate acerca del modo de caracterizar a esas mismas prácticas, a las que - por una cuestión de economía de palabras, y dado que su discusión excede el objeto de este trabajo- Llamo "alternativas", aunque bien podrían denominarse "complementarias", "marginales", "irregulares" o "heterodoxas", entre otros adjetivos. Cfr. Matthew Ramsey, op. cit.; James Bradley, "Medicine on the margins? Hydropathy and orthodoxy in Britain, 1840-60", en
A continuación, me propongo recuperar las experiencias de dos de los más importantes referentes de la medicina naturista, los ya mencionados: Vincent Priessnitz y Sebastian Kneipp. Revisaré algunas de las formas por medio de las cuales sus enseñanzas fueron difundidas y adoptadas en distintos países, deteniéndome — como referí antes - en ciertas experiencias de militancia que asumieron sus métodos como parte de un proyecto más amplio de transformación social, y en algunas de las características que las mismas tomaron durante los primeros años de su difusión en España.

\subsection{La hidropatía de Vincent Priessnitz}

En una conferencia brindada el 5 de julio de 1918 en la Sociedad Naturista Vegetariana de Valencia - cuyo texto fue publicado cuatro años más tarde por el Instituto Naturista Hispano Americano-, Rosell afirmó que, en su aspecto exclusivamente terapéutico, la razón de ser del naturismo radicaba en la desorientación en la que se encontraba la medicina oficial. Frente al laberinto sin salida al que habría arribado la historia de los saberes destinados al cuidado de la salud, el conferencista proponía desandar el camino hacia "las enseñanzas y prácticas de Hipócrates, adaptadas al tiempo y hermanadas con las intuiciones de un Priessnitz", a quien - a diferencia de otros pretendidos naturistas que sólo se interesaban en comerciar - consideraba como "un hermoso caso de intuición feliz en hidroterapia..."11

Vincent Priesnitz fue un campesino silesiano que, hacia fines de la década de 1820, fundó en la localidad austríaca de Gräfenberg (actual localidad checa de Jeseník) un establecimiento de hidropatía cuyas repercusiones producirían un clivaje en la historia del uso del agua como elemento de curación. Nacido en 1779, los primeros ensayos de Priessnitz con la salud —según narra uno de sus principales biógrafos, Richard Metcalfe ${ }^{12}$ - fueron prácticas curativas realizadas consigo mismo sobre distintas lesiones sufridas mientras trabajaba en la granja de su familia, algunas de las cuales los expertos que lo atendieron habrían considerado incurables. Ante la efectividad experimentada en

Waltraud Ernst (ed.), Plural Medicine, Tradition and Modernity, 18002000, Nueva York, Routledge, 2002, pp. 19-39; James Bradley y Marguerite Dupree, "A Shadow of Orthodoxy? An Epistemology of British Hydropathy, 1840-1858", en Medical History, n 47, 2003, pp. 173-194; Roberta Bivins, Alternative Medicine? A History, Nueva York, Oxford University Press, 2007. Otra discusión que se desprende de aquella, y que resulta importante tener presente, gira en torno a la relación entre saberes expertos y profanos en los procesos de producción, circulación y divulgación de las ciencias médicas. Cfr. Agustí Nieto-Galan, Los públicos de la ciencia. Expertos y profanos a través de la historia. Madrid, Marcial Pons, 2011.

11 Albano Rosell, Naturismo en acción, Barcelona, Instituto Naturista Hispano Americano, 1922, pp. 51 y 59.

12 Richard Metcalfe, Life of Vincent Priessnitz. Founder of Hidropathy, Londres, Simpkin, Marshall, Hamilton, Kent and Co., 1898. 
el uso de compresiones húmedas y otras técnicas consistentes en la realización de distintos tipos de baños de agua fría, el silesiano comenzó a ofrecer sus servicios entre sus allegados y fue haciéndose de una popularidad que trascendió las fronteras de su pueblo. Personas de distintas regiones empezaron a visitar Gräfenberg solicitando su atención, motivo por el cual acabó instalando un establecimiento de hidropatía que llegó a recibir la consulta de cerca de mil quinientos pacientes por año hacia fines de la década de 1830.

Algunas de las personas que visitaron el establecimiento de Priessnitz se prestaron luego a la difusión de sus métodos a través de la publicación de libros en los que narraron la experiencia en el lugar. Entre ellos se encontró un empresario británico de nombre Richard Tappin Claridge, reconocido en su país por ser uno de los primeros en utilizar asfalto para pavimentación. Tras la búsqueda de una cura contra el reumatismo y los persistentes dolores de cabeza que sufría, Claridge arribó a Gräfenberg junto a su familia en 1840. Dos años más tarde, escribió y publicó un libro titulado Hydropathy; or, The Cold Water Cure, as practiced by Vincent Priessnitz. En él dio testimonio de su experiencia de sanación, acompañada por una selección de escritos sobre el tema de distintos médicos que visitaron el establecimiento y un compendio de diferentes técnicas de hidroterapia. Traducido al castellano en 1843, éste fue el primer libro sobre los métodos de Priessnitz que circuló en España.13

Si bien era el agua fría la protagonista principal de los tratamientos impartidos en Gräfenberg, Claridge refería que allí también se hacía uso de los poderes curativos de otros elementos de la naturaleza como el aire. Priessnitz recomendaba a quienes visitaban su establecimiento que mantuvieran las ventanas de sus cuartos abiertas para que el libre ingreso de aire fresco colaborara en la tarea de purificación de los organismos. Asimismo, en el lugar se mantenía una dieta regimentada en la que se prohibía el consumo de bebidas alcohólicas, mostazas y pimientas, se promovía el consumo de leche, pan y, por supuesto, gran cantidad de agua. También se indicaba la realización de diferentes ejercicios al aire libre para distintos horarios del día, desde largas caminatas hasta la recolección y tala de madera. A diferencia de los balnearios y spas que ya existían desde hace rato en Europa, las instalaciones de Gräfenberg se caracterizaban por su relativa austeridad.14 Ésta era presentada como parte constitutiva de los tratamientos, para los cuales la adopción de una vida sobria resultaba fundamental a los fines de alcanzar el autocontrol de los placeres considerados superfluos y perjudiciales para la

13 Siete años más tarde, en 1850, el libro fue publicado en Buenos Aires por la Imprenta Americana. Richard T. Claridge, Hidropathia, o cura por medio del agua fría, según la práctica de Vicente Piressnitz, en Graefenberg, en Silesia, Austria, Buenos Aires, Imprenta Americana, 1850.

14 Sobre la historia de los spas y sus usos terapéuticos, Roy Porter (ed.), The Medical History of Waters and Spas. Medical History, Supplement $\mathbf{n}^{\circ} \mathbf{1 0}$, Londres, Welcome Institute for the History of Medicine, 1990. salud. De esta forma, lejos de reducirse a una técnica específica destinada a la cura de una determinada enfermedad, el método de Priessnitz podía comprenderse como la propuesta de un completo cambio en ciertos modos de conducta. Su resultado —afirmaba Claridge — apuntaba a "reformar física y moralmente la condición del género humano tal vez más que con ningún otro [descubrimiento] desde el principio del cristianismo".15 Quienes lo adoptaran para sí, prometía el autor, podrían alcanzar una vida saludable y longeva.

La relación entablada con la práctica de la hidropatía fue bien distinta en cada una de las regiones donde los métodos de Priessnitz fueron difundidos. En España, el primer establecimiento hidroterapéutico fue creado en Málaga por Vicente Ors, un médico que en 1844 visitó Gräfenberg para conocer de primera mano los tratamientos que allí se practicaban. A diferencia de lo ocurrido en otros países de Europa —afirma Juan RodríguezSánchez-, quienes en España ensayaron los métodos del silesiano fueron, como Ors, médicos diplomados para los que el uso terapéutico del agua no venía a reemplazar el ejercicio de la ciencia médica, sino a complementarla. Por su parte, quienes fueron tratados con tales técnicas no acostumbraron a practicarlas por sí mismos, es decir, sin la previa recomendación de expertos en medicina. $Y$ tampoco manifestaron experiencias de conversión como las que refiere el escrito de Claridge, en las que enfermos curados por el poder del agua comenzaban a "profesar una nueva vida, filosofía o religión". De este modo, la hidroterapia "quedó reducida a mera técnica". ${ }^{16}$

Mientras tanto, en Gran Bretaña, la difusión y práctica de la hidropatía tuvieron algunas peculiaridades que, a los fines de este artículo, resultan importantes referir. Durante la segunda mitad del siglo XIX se creó allí una gran cantidad de establecimientos hidropáticos, muchos de ellos financiados por empresarios como Claridge y administrados por médicos diplomados. ${ }^{17}$ Pero también se editaron diversos manuales que permitieron que

\section{Richard T. Claridge, op. cit., p. IV.}

16 Juan A. Rodríguez-Sánchez, "Una alternativa restringida: La introducción de la hidropatía en España", en Elvira Arquiola y José Martínez-Pérez (eds.), Ciencia en expansión: estudios sobre la difusión de las ideas científicas y médicas en España (siglos XVIII-XX), Madrid, Editorial Complutense, 1995 , pp. 322-349, pp. 343 y 344 . Sin intenciones de extenderme demasiado, quisiera apenas señalar que el hecho de que sean médicos diplomados quienes ensayaron los métodos de Priessnitz no implica que no puedan haberlos considerado bajo la forma de un cambio en los modos de conducta. Tal fue el caso de Francia, donde médicos que profesaban los postulados hipocráticos sobre la vis natura medicatrix promovieron una "hidroterapia vitalista" como reforma de los estilos de vida, mientras otros más cercanos a la medicina experimental practicaron una "hidroterapia positiva" en tanto técnica de curación específica para determinadas enfermedades. Arnaud Baubérot, "Les vicissitudes de l'hydrothérapie en France", en Histoire du naturisme. Le mythe du retour à la nature, Rennes, Presses universitaires de Rennes, 2015, p. 60

17 De allí que — como refieren Bradley y Dupree - la dicotomía entre medicina ortodoxa y heterodoxa no permita comprender bien la historia de la hidropatía en Gran Bretaña. James Bradley, op. cit.; James Bradley y Marguerite Dupree, op. cit. 
muchas personas que no contaban con los recursos necesarios para afrontar el pago de los tratamientos pudieran ensayar tales métodos terapéuticos al interior de sus hogares. Entre las principales difusoras de este tipo de aplicaciones se encontró la activista estadounidense por los derechos de las mujeres Mary Gove Nichols, quien arribó a Inglaterra a comienzos de la década de 1860. Allí publicó el libro A Woman's Work in Water Cure and

Sanitary Education, en el que promovió el uso de la hidropatía durante el embarazo y como técnica para aliviar el dolor en la instancia de parto. ${ }^{18}$ A diferencia de quienes la practicaban como una técnica exclusivamente terapéutica, Nichols hizo de los métodos de autocuidado a través del uso del agua parte de una estrategia más amplia de reforma. La misma abarcó una serie de tópicos afines a aquellos que, posteriormente, serían problematizados por varios militantes anarquistas practicantes del naturismo: el cambio en los modos de vestimenta y en los vínculos afectivos, el vegetarianismo, el control de la natalidad y el rechazo al uso de las vacunas. ${ }^{19}$

Asimismo, algunos años antes de la llegada de Nichols a Inglaterra, integrantes de los movimientos cartista y owenista habían también ensayado el método de la hidropatía como modo de conducta orientada a la transformación de sus estilos de vida. En un trabajo dedicado a analizar la política moral de los movimientos contestatarios de la época victoriana, Tom Scriven considera que el recurso a "formas politizadas del cuidado de la salud" fue uno de los medios utilizados por ciertos grupos de trabajadores para "combatir una sociedad industrializada y competitiva". ${ }^{20}$ El ensayo con métodos hidropáticos y otras técnicas de medicina alternativa —además del rechazo al consumo de alcohol y la adopción de una dieta vegetarianase produjo en el marco de la promoción de una cultura de autocuidado destinada a la modulación de las conductas a través de la sobriedad y la temperancia.

\subsection{Sebastian Kneipp y la difusión del naturismo en España}

Como comenté recién, los escritos de personas que visitaron

18 Mary Gove Nichols, A Woman's Work in Water Cure and Sanitary Education, Londres, Nichols and Co., 1874, p. 96.

19 Hilary Marland y Jane Adams, "Hydropathy at Home: The Water Cure and Domestic Healing in Mid-Nineteenth-Century Britain", en Bulletin of the History of Medicine, Vol. 83, n³, 2009, pp. 499-529.

20 Tom Scriven, Popular virtue. Continuity and change in Radical moral politics, 1820-70, Manchester, Manchester University Press, 2017, p. 104. El autor refiere que, tras la publicación del libro de Claridge, el líder cartista John Cleave escribió en 1843 un editorial elogiando la belleza de "esa ciencia que nos enseña a considerar que la naturaleza otorga los medios para renovar la salud, donde sea que haya provocado que las fuentes broten o el arroyo corra". Cit. en ibídem, p. 122. Cfr. también J. F. C. Harrison, "Early Victorian Radicals and the Medical Fringe", en William F. Bynum y Roy Porter (ed.), op. cit., pp. 198-215
Gräfenberg y narraron su experiencia en el lugar, junto a los manuales de hidroterapia escritos por expertos y profanos en la ciencia médica, propiciaron la experimentación con los poderes curativos del agua en contextos diversos. También el ensayo con otros métodos de sanación que incluyeron el aprovechamiento de la luz del sol, del aire libre y de los componentes nutricionales de los alimentos. Varias de estas nuevas formas de experimentación en el cuidado de la salud se produjeron en Alemania, donde, algunos años después de la muerte de Priessnitz, un médico militar de nombre Lorenz Gleich propuso la noción de Naturheilkunde (medicina naturista) en reemplazo de la de Wasserheilkunde (hidroterapia). Haciéndose eco de esta propuesta de renovación terminológica, el editor de la por entonces reconocida revista Der Wasserfreund (El amigo del agua), Wilhelm Meinert, rebautizó en 1863 su publicación con el nombre de Der Naturzarzt (El médico naturista).. ${ }^{21}$ Dos décadas más tarde se crearía la primera sociedad naturista de alcance nacional: la Asociación Alemana para la Medicina Naturista e Higiene Popular. ${ }^{22}$

En el centro de Europa, el ejercicio de la medicina naturista tomó distintas modalidades según las diferentes formas en que se relacionaron con ella quienes practicaron y difundieron sus métodos. Por un lado, se constituyó en un fenómeno comercial que produjo a los dueños de establecimientos terapéuticos importantes ingresos en la prestación de sus servicios y en la venta de sus productos a sectores de la burguesía. Por otro, adquirió la forma de práctica filantrópica que promovió la implementación de métodos curativos de bajo costo y al alcance de los sectores populares. Finalmente, el naturismo fue adoptado como conducta ética y estética por integrantes de movimientos como la Lebensreform (reforma de la vida). Estos movimientos encontraron en la hidroterapia, la helioterapia, el vegetarianismo y el nudismo - entre otras prácticas luego ensayadas también por anarquistas, como la huida de la ciudad y la creación de colonias rurales - una respuesta crítica a los cambios en los modos de vida producidos por el desarrollo de la modernidad y por la industrialización. ${ }^{23}$

Como señalé antes, dos de los referentes más importantes para el desarrollo del naturismo fueron Sebastian Kneipp y Louis Kuhne. A raíz de la relevancia que la difusión de sus libros y la venta de sus productos tuvo en la conformación de las primeras

21 Alejandro Artetxe, Historia de la medicina naturista española, Madrid, Triacastela, 2000, pp. 59-61. El autor toma la decisión de traducir Naturheilkunde como "medicina naturista", aunque refiere también otras posibles acepciones como "terapéutica natural" o "terapéutica naturista". Asimismo, otras traducciones posibles podrían ser "naturopatía" o "naturismo", nociones utilizadas a fines del siglo XIX y principios del XX por los practicantes naturistas de habla hispana de manera, muchas veces, indiferenciada.

22 Arnaud Baubérot, op. cit., p. 36

23 Sobre la relación del naturismo con el movimiento de reforma de la vida, cfr. Arnaud Baubérot, "Du naturisme au nudisme", en op. cit., pp. 37-41; Alejandro Artetxe, op. cit., pp. 75-76. 
sociedades naturistas de España, me detendré especialmente en el primero de ellos. Sin embargo, cabe mencionar, a propósito de Kuhne, que su libro La nueva ciencia de curar fue traducido al castellano en 1894, de manera casi simultánea — según él mismo refirió en el prefacio a la edición española - que a otros veinticuatro idiomas. ${ }^{24}$ Apenas un año más tarde, se conformaría en Buenos Aires la primera asociación de medicina naturista del Río de la Plata, bautizada con el nombre de "Sociedad Kuhnista". Kneipp fue un sacerdote cristiano nacido en 1824 en la región alemana de Baviera. ${ }^{25}$ De manera similar a Priessnitz y muchos otros referentes de la medicina naturista, en sus escritos cuenta que empezó a ensayar prácticas alternativas de la salud cuando, en su adolescencia, contrajo una enfermedad que los médicos que lo asistieron no supieron cómo tratar. Esas prácticas consistieron en la aplicación de baños de agua que, de manera autodidacta, aprendió a realizar a partir de la lectura de distintos tratados hidropáticos. Habiendo sido trasladado para ejercer el sacerdocio a la localidad de Wörishofen, instaló allí un establecimiento en el que llegó a atender a varios miles de personas de distintos sectores sociales. En 1886, prestó testimonio de sus métodos en un libro titulado Meiner Wasserkur, el cual apenas cinco años más tarde alcanzó su trigésima tercera edición y se tradujo a catorce idiomas. En España fue publicado en dos traducciones: una de 1892 con el título de Mi curación por el agua y otra, un año más tarde, titulada Método de hidroterapia. ${ }^{26}$

Además de la aplicación de técnicas hidropáticas, Kneipp practicó la herboristería y promovió ciertos cambios en los hábitos de conducta. Entre ellas se interesó particularmente por las conductas alimentarias y los modos de vestimenta, a cuyas malas costumbres atribuyó la causa de gran parte de las enfermedades que afectaban a las personas de su tiempo. El estado de salud que él mismo había alcanzado se debía, junto al uso curativo del agua, a haber seguido, "por espacio de más de 40 años, el buen método de vida, es decir, la manera y forma como me alimento, visto y duermo, la disposición de mi casa y todo cuanto hace relación a la higiene". ${ }^{27}$ Con el fin de dar a conocer tales métodos, se propuso la escritura de un segundo trabajo titulado Cómo

24 Louis Kuhne, La nueva ciencia de curar o enseñanza de la unidad de las enfermedades y su curación sin medicamentes y sin operaciones, basada en ella, Trad. de J. O. Monsterios e I. López Lapuya, $15^{\circ}$ edición española, s/d, p. VI.

25 Algunas de las referencias biográficas de Kneipp son tomadas de Friedhelm Kirchfeld y Wade Boyle, "The World's Most Famous Nature Doctor. Sebastian Kneipp (1824-1897)", en Nature Doctors. Pioneers in Naturopathic Medicine, Portland, NCNM Press, 1994, pp. 73-98.

26 Sebastian Kneipp, Método de hidroterapia, Trad. de Francisco García Ayuso, Barcelona, Juan Gili, 1909.

27 Sebastian Kneipp, Cómo habéis de vivir, Trad. de Francisco García Ayuso, Barcelona, Juan Gili, 1902, p. IX. Publicado en 1889, el libro fue traducido al castellano en 1892, cuando iba por su trigésimo tercera edición en alemán y llevaba vendidos más de 160 mil ejemplares. Por otra parte además de sus libros, las noticias acerca de las técnicas en hidroterapia ensayadas por el sacerdote fueron difundidas en España a través de la publicación, entre 1894 y 1898, del Almanaque Kneipp. En él se reproducían los testimonios de personas que habían visitado Wörishofen y experimentado la eficacia de los tratamientos impartidos. habéis de vivir. En él, junto a los temas recién señalados, abordó cuestiones relativas al ejercicio físico, el trabajo, el descanso y la educación.

Inicialmente, la difusión en España de las ideas del sacerdote se produjo a través de dos vías. A propósito de la primera, que podríamos llamar la vía religiosa y filantrópica, RodríguezSánchez analiza la fuerte influencia que la formación eclesiástica de Kneipp tuvo en sus escritos sobre la salud. Mientras ésta - afirma el autor - era considerada por el sacerdote como un "don divino", la enfermedad lo era como un "pecado o castigo". "El abate alemán funde higiene y religión en una emponzoñada mezcla en la que la búsqueda de la salud física es temor al castigo eterno del alma..."28 Apoyándose en el esquema del mito cristiano de la caída, las malas condiciones de vida de la sociedad moderna fueron interpretadas por el sacerdote como una degeneración. Frente a ellas venía a ofrecer una respuesta el simbolismo que, desde el siglo XVIII, atribuía al agua fría virtudes regenerativas de carácter físico y moral. ${ }^{29} \mathrm{~L}$ a propagación de estas concepciones higiénico-religiosas y, junto a ellas, de los métodos de cura a los que Kneipp imputaba efectos casi milagrosos se vieron favorecidas por su nombramiento como Camarero Privado del Papa León XIII, autor de la encíclica social Rerum Novarum. Fue en el marco de esta nueva política del Vaticano que se fortalecieron los círculos de obreros católicos que en España ya existían desde $1861 .{ }^{30} \mathrm{El}$ fundador en Madrid de uno de ellos fue Francisco García Ayuso, traductor al castellano de las obras de Kneipp y propagandista de sus ideas de reforma física y moral en conferencias dirigidas a los trabajadores. ${ }^{31}$ De esta manera, la regimentación de las conductas orientadas al cuidado de la salud que el sacerdote proponía comenzaría a formar parte de una estrategia de sectores católicos destinada a introducir cambios en las formas cotidianas de vida de los obreros.

La otra de las vías por medio de las cuales los métodos de

28 Juan A. Rodríguez-Sánchez, "Moralismo higiénico: la terapéutica del abate Kneipp y su introducción en España", en Luis Montiel e Isabel Porras (coords.), De la responsabilidad individual a la culpabilización de la víctima. El papel del paciente en la prevención de la enfermedad, Aranjuez, Doce Calles, 1997, pp. 33-54, p. 41

29 Georges Vigarello, Lo limpio y lo sano. La higiene del cuerpo desde la Edad Media, Madrid, Alianza Editorial, 1991.

30 Lily, Litvak, op. cit., p. 50

31 Juan A. Rodríguez-Sánchez, "Moralismo higiénico...", op. cit., p. 51. Cabe señalar que la interpretación de la enfermedad y la salud como efecto, respectivamente, de la degeneración y la regeneración no fue exclusiva de los círculos católicos. Dicho esquema eugenésico se encontraba también fuertemente arraigado en anarquistas y naturistas. Acerca de la particularidad que asumió la perspectiva eugenésica en el anarquismo español, cfr. Richard Cleminson, "La recepción de la eugenesia en el anarquismo, 1910-1935", en Anarquismo y sexualidad en España (19001939), Cádiz, Servicio de Publicaciones de la Universidad de Cádiz, 2008 , pp. 77-128; Jorge Molero Mesa e Isabel Jiménez Lucena, "'Otra manera de ver las cosas'. Microbios, eugenesia y ambientalismo radical en el anarquismo español del siglo XX", en Marisa Miranda y Gustavo Vallejo (eds.), Darwinismo social y eugenesia. Derivas de Darwin: cultura y política en clave biológica, Buenos Aires, Siglo XXI, 2010, pp. 143-164. 
Kneipp comenzaron a ser difundidos en España fue la vía comercial. Además de la prestación de servicios curativos en su establecimiento y de la venta de sus libros, el sacerdote se dedicó a la fabricación, en acuerdo con distintas compañías, de una serie de productos alimenticios, farmacéuticos y de vestimenta a los que atribuyó cualidades beneficiosas para la salud. Se constituyó entonces, en gran parte de Europa y otras regiones del mundo, una red de comercios que contaban con presunta autorización oficial para la venta de pan Kneipp, café de malta Kneipp, sandalias Kneipp, cereales Kneipp, extractos de hierbas Kneipp. En esta suerte de fervor generado en torno al nombre del sacerdote naturista, tras visitar el establecimiento de Wörishofen a comienzos de la década de 1890, el comerciante barcelonés Jaime Santiveri transformó su local de ropas en la primera "Camisería higiénica Sistema Kneipp" de España. Dado que el sacerdote consideraba insalubre la utilización de prendas demasiado abrigadas, el comercio de Santiveri las ofrecía confeccionadas exclusivamente con lino o, como también le Llamaba, "lino salud". Poco después, en 1893, abrió un nuevo local contiguo al primero dedicado a la venta de otros productos de la marca alemana. ${ }^{32}$

Los locales de Santiveri se constituyeron en un centro de referencia para quienes en Barcelona buscaban ensayar prácticas alternativas del cuidado de la salud. Junto a la serie de productos Kneipp - y a pesar de que la dieta promovida por el sacerdote incluía el consumo de carne-, comenzó a ofrecerse una variedad de alimentos vegetarianos, y fue punto de suscripción y venta de La revista madrileña El régimen naturalista. Editada a partir de enero de 1904 por la recién constituida Sociedad Vegetariana Española, ésta fue la primera publicación periódica dedicada a la medicina naturista que apareció en España. En ella se aconsejaba la práctica de los métodos de Kneipp, Kuhne y otros naturistas famosos, así como la adopción de una dieta vegetariana, cuyos beneficios para las clases trabajadoras — según argumentabanresidían tanto en sus virtudes regenerativas como en su bajo costo. $^{33}$ Algunos años más tarde, en 1908 , se conformaría en Barcelona la Lliga Vegetariana de Catalunya y junto a ella comenzaría a publicarse la Revista Vegetariana, dirigida por Joseph Falp y Plana, y administrada por Santiveri.

A continuación, pasaré a revisar el modo en que Albano Rosell, tomando distancia de estas experiencias, se propuso conjugar el proyecto naturista de reforma de los estilos de vida con algunas de las críticas anarquistas a los modos de organización de la sociedad. Para ello — cabe antes señalar-, contaba con el antecedente de pequeños grupos de anarco-individualistas franceses que, hacia finales del siglo XIX, habían comenzado a ensayar conductas naturistas del cuidado de la salud como una práctica de rechazo a la civilización moderna y el desarrollo

32 Alejandro Artetxe, op. cit., pp. 83-84.

33 Ibídem, p. 88. industrial. ${ }^{34}$ Entre quienes formaron parte activa de estos grupos se encontraba Henry Zizly, autor de un artículo publicado el 15 de septiembre de 1902 en La Revista Blanca de Madrid. En él, el anarquista francés denunciaba "los numerosos males que asedian y rigen actualmente la humanidad: Ciencia, Maquinaria, Religión, Parlamento, Ejército", y llamaba a sus compañeros de ideas a avanzar hacia "el advenimiento de la Naturaleza integral." ${ }^{35}$ En su escrito antes citado, Naturismo en acción, Rosell reconocía los progresos realizados al respecto por "mi amigo H. Zizly", aunque consideraba que sus ensayos todavía carecían de un principio filosófico capaz de enlazar las distintas dimensiones de las que se compone el problema. ${ }^{36}$ Tal principio es el que buscó fundar con su concepción de naturismo integral.

\section{Albano Rosell: anarquista, pedagogo y naturista}

Nacido en la localidad catalana de Sabadell en 1881, Albano Rosell y Llongueras dejó la escuela a sus once años para comenzar a trabajar como hilador. Tres años más tarde, empezaría su trayectoria militante al interior del sindicato de tejedores. De manera temprana, comenzó a colaborar con distintas publicaciones anarquistas y dirigió el periódico El Trabajo, órgano de la Federación Obrera Sabadellense. Su afición por el teatro como herramienta de propaganda lo llevó a fundar en 1901 la Agrupación Dramática "Ibsen", a integrar el grupo Avenir dirigido por su amigo Felip Cortiella y a escribir varias obras, en su mayoría dirigidas a los niños. ${ }^{37}$ Durante su infancia, entabló amistad con Mateo Morral, con quien se reencontraría luego en la Federación Obrera, y sobre cuya vida publicó un extenso escrito a modo de folletín, firmado con el seudónimo de Antonio Roca, entre los meses de diciembre de 1932 y enero de 1933 en el periódico La Protesta de Buenos Aires. ${ }^{38}$

Junto a su actividad como naturista, la militancia anarquista

34 Sobre la relación entre anarquismo y naturismo en Francia, Arnaud Baubérot, "Troisième partie. Naturisme et anarchisme", op. cit., pp. 123-191.

35 Enrique Zizly, "Hacia la conquista del estado natural", en La Revista Blanca, año $\mathrm{VI}, \mathrm{n}^{\circ} 102$, Madrid, 15 de septiembre de 1902, pp. 167-170, pp. 168-169.

36 Además de Zizly, Rosell destacaba los aportes de Émile Gravelle y E. Armand, y la conducta vegetariana de otros anarquistas como Reclus, Tolstoi, Kropotkin, Albert y Tarrida del Marmol. Albano Rosell, op. cit., p. 68.

37 Sobre la producción teatral de Rosell, Lily Litvak, "Teatro anarquista", en op. cit., pp. 213-252.

38 Antonio Roca, "De la vida trágica de Mateo Morral. Recuerdos de juventud", en La Protesta, Buenos Aires, año XXXVI, n 7803, 10/12/1932, pp. 2-3. Se publica de manera ininterrumpida en once entregas hasta el $n^{\circ} 7813$ del 14 de enero de 1933. En 1940 Rosell realizó en Montevideo una copia mecanografiada del escrito con algunos pocos agregados. En su primera página, cuenta que el mismo fue redactado en 1931 a pedido de Diego Abad de Santillán, y lamenta que quienes "lo publicaron ejercieron cierta censura y mutilaron algunas cosas, aquellas que podrían parecerles desdorosas para el ideal, sin consultarme recabando mi conformidad". Antonio Roca, Vidas trágicas. Mateo Morral. Francisco Ferrer, Montevideo, copia mecanografiada, 1940, p. 4 
de Rosell se destacó por su labor como pedagogo. ${ }^{39}$ En 1904, tras entrar en contacto con la Escuela Moderna de Barcelona, Francisco Ferrer Guardia le encargó la dirección de una Escuela Moderna en Montgat que a poco de inaugurarse fue clausurada por las malas condiciones del local en que funcionaba. Este asunto motivó uno de los primeros desencuentros entre ambos pedagogos, quienes terminarían de distanciarse luego del fallido atentado de Morral contra Alfonso XIII en 1906. En un libro dedicado a revisar las controversias entre Rosell y Ferrer, Pere Solà Gussinyer define al primero como "el puritano anarquista, que sigue la acción colectiva en una dinámica de lucha de clases en la que se instala, pero que en el fondo es un libertario individualista, celoso de la perfección y la pureza individual hasta el fanatismo".40 El carácter individualista de Rosell, sin embargo, no lo llevaba a buscar hacerse de un nombre con el cual alcanzar cierto reconocimiento. Por el contrario, expresó en un artículo firmado con el seudónimo de Laureano D'Ore y publicado en el periódico El Naturista que él mismo fundó en 1922:

he hecho todo lo posible en todos los actos que tienden a evidenciarse ante las masas, de pasar desapercibido, de pasar ignorado, de ser desconocido. [...] Yo he escrito casi siempre en pseudónimos, y cuando uno de ellos, por cualquier causa, Llegaba a ser conocido, lo abandonaba, anheloso de que no se fijaran con quien lo escribe, sino con lo que se dice, y si se acepta, se cumpla lo mejor que se pueda. Se me ha pedido en varias ocasiones la fotografía para ser publicada en revistas y otros impresos, y siempre la he negado, porque me repugna ese exhibicionismo santón. [...] Creo que si yo hubiese tenido la manía de ser pastor, apóstol o único, todo ello habría acontecido de muy otra manera, y no hubiera despreciado las varias ocasiones que se me han ofrecido para ser personaje, director, inspirador, caudillo. ${ }^{41}$

Además de los ya citados Antonio Roca y Laureano D' Ore, otros de sus seudónimos fueron: Héctor Thales, El Otro, Dr. Frank Aube, Germina Alba y Dr. Zeda, X. Siguiendo la producción de esta multiplicidad de alter egos, puede encontrarse que gran parte de los artículos de periódicos que dirigió fueron escritos por él, aunque, claro, figuren a título de distintos autores. Asimismo, esta cuidada política onomástica lo llevó a escribir libros atribuyendo la autoría a alguno de sus seudónimos, para luego prologarlos bajo el nombre de otro, e incluso lo condujo a

39 Otra militante anarquista española, nacida casualmente el mismo año que Rosell, que se dedicó también a ambas esferas de actividad, fue la pedagogía libertaria y la medicina naturista Antonia Maymón. Sobre su vida, militancia y pensamiento, María Carmen Agulló Díaz y María Pilar Molina Beneyto, Antonia Maymón. Anarquista, maestra, naturista, Barcelona, Virus editorial, 2014.

40 Pere Solà i Gussinyer, Ferrer Guardia. Pedagogo y hombre de acción. La mirada apasionada de Alban Rosell sobre el fundador de la Escuela Moderna, Clavell, Gobierno de España, Ministerio de Cultura, 2011, p. 32.

41 Laureano D' Ore, "Sendas tortuosas", en El Naturista, Carlet, año I, n 5, 10/04/1922, pp. $32-33$, p. 32 asumir el cargo de director de la Escuela Integral de Montevideo con el nombre Laureano D' Ore.

Tras el estallido de la "semana trágica" de Barcelona, el posterior cierre de las escuelas racionalistas y el destierro de sus profesores, Rosell se exilió en Francia y partió de allí a Buenos Aires. En la ciudad porteña dirigió la Escuela Moderna de Villa Crespo durante un corto tiempo, hasta su clausura después del atentado de Ramón Falcón. ${ }^{42}$ Luego de ser detenido y pasar seis días preso, se trasladó a Montevideo — según sus propias palabras"para ver si había mejor ambiente".43 Allí se quedó hasta 1915, cuando volvió a España y, cerca de siete años más tarde, retornó definitivamente a la capital uruguaya. Entre los proyectos de los que participó durante su primera etapa montevideana, se destacan la edición de la revista Infancia y la creación de la Liga Popular para la Educación Racional de la Infancia. ${ }^{44}$ Luego, a su regreso, creó la revista y editorial Analectos.

Así como muchos de quienes practicaron el naturismo comenzaron a hacerlo después de pasar por una crisis de salud, la experiencia de Rosell con tales métodos curativos empezó después de que en 1907 falleciera uno de sus hijos víctima de una enfermedad que médicos diplomados no supieron tratar. ${ }^{45} \mathrm{~A}$ partir de entonces, se propuso desarrollar — de manear similar a otros compañeros de ideas como los ya referidos Antonia Maymón y Federica Montseny, y como Isaac Puente, Eusebio Carbó y Manuel Costa-Iscar - una articulación entre ciertas dimensiones del proyecto naturista y la crítica anarquista a la sociedad. Los desarrollos de Rosell se encuentran plasmados en varios de sus artículos, libros y otros escritos que no llegaron a publicarse, destacándose como momento de mayor producción el período comprendido entre 1918 y 1922, durante el cual residió en la región de Valencia. ${ }^{46}$ A continuación, me centraré

42 En enero de 1910, la revista Ideas y figuras informó sobre la clausura de la Escuela de Villa Crespo y detención de Rosell. Anónimo, "Crónica", Ideas y figuras, Buenos Aires, Año II, n²3, 11/01/1910. Sobre la Escuela Moderna de Villa Crespo, Dora Barrancos, Anarquismo, educación y costumbres en la Argentina de principios de siglo, Buenos Aires, Editorial Contrapunto, 1990, pp. 127-128.

43 Albano Rosell, Rasgos y anécdotas de algunas personas, Montevideo, copia mecanografiada, 1957, p. 28.

44 Gerardo Garay Montaner, "La discusión en torno a la implementación de la Escuela Integral en el marco de la propaganda racionalista en Montevideo, 1911-1916", en Revista Latino-Americana de Historia, Vol. 6, n 17, junio-julio de 2017, pp. 7-26; Gerardo Garay Montaner, "Anarquistas y racionalistas en el marco de la 'Liga Popular para la Educación Racional de la Infancia'. Montevideo, 1911-1916", en Avances del Cesor, Vol. XIV, nº 17, julio-diciembre de 2017, pp. 39-61.

45 Albano Rosell, Recuerdos de juventud, cit. en Pere Solà i Gussinyer, op cit., pp. 148-149.

46 Valencia fue, junto a Barcelona y Madrid, uno de los principales centros de difusión del naturismo en la península ibérica. Allí se editaron las revistas Helios (sobre la cual me referiré a continuación) y, tras el retorno de Rosell a Montevideo, Generación Consciente, que luego tomaría el nombre de Estudios. Acerca de estas últimas, Francisco Javier Navarro Navarro, "Anarquismo y Neomalthusianismo: la revista Generación Consciente (1923-1928)", en Arbor, Vol. CLVI, n 615, marzo de 1997, pp. 9-32; Francisco Javier Navarro Navarro, "El paraíso de la razón". La revista Es- 
en los cuestionamientos que, por aquellos años, realizó a las aplicaciones exclusivamente terapéuticas del naturismo y a su utilización con fines comerciales, para luego pasar a revisar su concepción de naturismo integral como proyecto de reforma de los estilos de vida.

\subsection{Críticas al naturismo terapéutico y comercial}

En 1918 un conjunto importante de sociedades naturistas de la península ibérica se preparaba para la celebración de un Congreso Internacional que tendría lugar durante el mes de diciembre en Lisboa. Rosell iría en representación de la Sociedad Vegetariana Naturista de Valencia, mientras que otro reconocido militante anarquista, Eusebio Carbó, lo haría en nombre de la revista Helios. ${ }^{47}$ En su trabajo La ecología humana en el anarquismo ibérico, Eduard Masjuan considera que se trató de "[l]a gran oportunidad de los partidarios del naturismo como ideario social emancipador" ${ }^{48}$ Sin embargo, a último momento, cuando Rosell ya había incluso arribado a la capital portuguesa, el Congreso fue suspendido. La ponencia que escribió para presentar se titulaba Naturismo y educación de la infancia. ${ }^{49} \mathrm{El}$ mismo año, escribió otro texto a pedido del director de una revista naturista que no llegó a publicarse, El naturismo integral y el hombre libre, y dictó dos conferencias en el local de la sociedad a la que iba a representar en Lisboa.50 Años más tarde, esas conferencias serían publicadas como la primera y segunda parte del Bosquejo sobre filosofía naturista. Aspecto médico-social de la dignidad humana y también se editaría la ya citada Naturismo en acción. ${ }^{51}$

A diferencia de otros referentes del naturismo, Rosell no sentía un rechazo absoluto por los médicos diplomados, aunque sí por varias de las formas de tratamiento que éstos practicaban

tudios (1928-1937) y el mundo cultural anarquista, Valencia, Edicions Alfons el Magnànim - IVEI, 1997.

47 La revista valenciana Helios, una de las más importantes publicaciones naturistas de España, comenzó a editarse en enero de 1916 y, tras la conformación de la Sociedad Vegetariana Naturista en marzo de 1917, se constituyó en su órgano oficial, a pesar de lo cual la revista y la Sociedad designaron cada una un delegado distinto para el Congreso.

48 Eduard Masjuan Bracons, La ecología urbana en el anarquismo ibérico: urbanismo "orgánico" o ecológico, neomalthusianismo y naturismo social, Barcelona, Icaria, Madrid, Fundación de Estudios Anselmo Lorenzo, 2000, p. 443. Sobre el pensamiento naturista de Carbó expuesto en el texto que preparó para el Congreso, luego publicado con el título de En la línea recta, ibidem, pp. 446-449.

49 Albano Rosell, Naturismo y educación de la infancia, Valencia, copia mecanografiada, 1918.

50 Albano Rosell, El naturismo integral y el hombre libre, Montevideo, copia mecanografiada, s/f. Como referí, el texto fue inicialmente escrito en Valencia en 1918, pero Rosell lo reescribió varios años más tarde, circa 1950, encontrándose nuevamente en Montevideo, y entonces le agregó varias notas al pie.

51 Albano Rosell, Aspecto médico-social de la dignidad humana, Barcelona, Instituto Naturista Hispano Americano, 1921, Albano Rosell, Naturismo en acción, op. cit. con sus pacientes. Así, rescataba en algunos pasajes de sus escritos el pensamiento de figuras reconocidas de la medicina uruguaya como Mateo Legnani y Santín Carlos Rossi, al tiempo que manifestaba una condena irrestricta al uso de medicamentos alopáticos, sueros y vacunas. ${ }^{52}$ Luego, a este tridente terapéutico, objeto de condena unánime por el conjunto de los practicantes de la medicina natural, sumaba otra serie de críticas a los médicos diplomados que dirigía por extensión también a los naturistas. Sus críticas partían de un cuestionamiento a la segmentación disciplinaria de saberes entre la medicina y la sociología, la ciencia encargada de velar por la salud física del cuerpo individual y aquella presuntamente dedicada a abordar los desórdenes de la vida en sociedad.

Para Rosell, la sociología y la medicina son dos ramas "que deben conducir a un mismo fin de bienestar y de felicidad humanas". 53 Sin embargo, se lamentaba de que, salvo raras excepciones, el desarrollo de ambas disciplinas haya corrido por carriles separados. Abstraídos en sus conocimientos sobre el funcionamiento del organismo, los médicos se habrían desinteresado de la elaboración de proyectos que tendieran a resolver los problemas que conciernen a las condiciones de vida y explotación de sus propios pacientes. Sumado a esta división de saberes, Rosell apuntaba contra el aislamiento en el que, una vez diplomados, solían replegarse los profesionales de la salud a fin de asegurarse la comodidad de una existencia al margen de las contrariedades con las que, de manera cotidiana, debían lidiar los sectores populares. El autor no desconocía experiencias como las de extensión universitaria o de los ateneos de cultura popular, así como tampoco la trayectoria de médicos dedicados a intervenir en las pautas de conducta social y a ensayar estrategias de intervención sobre el medio en que vivían los trabajadores. Sin embargo, encontraba que éstas no tenían por objeto propiciar la integridad física y moral de las personas, sino producir "un mayor rendimiento y perfección del valor hombre máquina". ${ }^{54}$ Fue éste el principal reproche que dirigía a los médicos, a quienes denunciaba como cómplices, sino responsables, del "crimen de lesa dignidad humana".

Si así no fuese, en vez de habilizar inteligencias y físicos, habrían abierto pensares, evidenciado injusticias, condenado explotaciones, revelado verdades; habríanle dicho al pueblo toda la razón que le asiste, si alguna vez intenta rebelarse contra las pésimas condiciones de sus viviendas, de las fábricas en que produce, de los talleres donde se lo encierra, lo mezquino de su salario que no le permite vivir, lo

52 Sobre el pensamiento de Mateo Legnani y Santín Carlos Rossi, quienes - a través de la lectura de la obra de escritores por los que Rosell sentía afinidad, como Tolstoi e lbsen-identificaban prevención de la salud con "moral fisiológica", Juan Pedro Barrán, "Biología, medicina y eugenesia en Uruguay", en Asclepio, Vol. LI, n², 1999, pp. 11-50.

53 Albano Rosell, Aspecto médico-social..., op. cit., p. 17. 54 Ibídem, p. 21 
abrumador del horario que le agota y embrutece; le habrían, en fin, abierto las potencias pensantes y las idealidades equitativas, antes que darle normas profilácticas e higiénicas que no puede cumplir; [...] antes que cantarle las bellezas y bondades de los ejercicios físicos y de la estética de nuestro organismo, deformado constantemente por la brutal permanencia de horas y más horas ante máquinas y bufetes, en forzadas posiciones, que llegan a convertirse en hábitos, dentro de insalubres recintos... ${ }^{55}$

Claro que no había, en estos postulados, argumentos muy distintos a los que manifestaba lo que Jorge Molero Mesa e Isabel Jiménez Lucena Llamaron el "ambientalismo radical" del anarquismo, para el cual la causa de toda enfermedad se hallaba, en última instancia, en la injusticia del orden social. ${ }^{56}$ Cabe precisar, al respecto, que uno de los anarquistas españoles que más influyó en el desarrollo de esta perspectiva, buscando articularla — tal analizan los recién citados autores y Richard Cleminson - con una propuesta eugenésica, fue el médico Isaac Puente, practicante también del naturismo. ${ }^{57}$ En este sentido, la novedad del planteo de Rosell residía menos en su concepción sociológica de la medicina que en la interpelación que con ella buscaba producir en el público al cual iban dirigidas sus palabras. Los fragmentos citados corresponden a una conferencia dictada ante un grupo de naturistas, para quienes las críticas doctrinales del anarquismo al modo de organización social no eran tan habituales en sus publicaciones. Así, Rosell ponía a circular argumentos propios del discurso libertario en un ámbito en cierto modo ajeno a éstos. Por otro lado, si bien su definitivo distanciamiento de la Sociedad Vegetariana Naturista de Valencia se produciría algunos años más tarde y por cuestiones económicas, por entonces el conferencista ya mostraba profundas diferencias con la forma en que integrantes de ésta y otras sociedades afines practicaban el naturismo. ${ }^{58} \mathrm{Y}$ el modo en que buscó expresarlas fue llevando los cuestionamientos a la medicina oficial hacia quienes decían no tener nada que ver con ésta.

Rosell acordaba con los médicos naturistas en que muchos de sus métodos habían significado un importante avance en la historia de los saberes destinados al cuidado de la salud, y

55 lbídem, p. 22.

56 Jorge Molero Mesa e Isabel Jiménez Lucena, op. cit.

57 Richard Cleminson, op. cit. La figura de Isaac Puente, fusilado por las tropas franquistas al inicio de la guerra civil, resulta paradigmática en tanto fue uno de los pocos anarquistas diplomados en medicina que practicaron y difundieron abiertamente el naturismo. Sobre su vida y obra, Francisco Fernández de Mendiola, Isaac Puente. El médico anarquista, Tafalla, Editorial Txalaparta, 2007.

58 En 1922, tras varias idas y vueltas en torno al uso que se daría al dinero recaudado para su participación en el malogrado Congreso, la Sociedad Vegetariana Naturista solicitó a Rosell su conformidad para enviar el dinero a Rusia como ayuda económica para combatir el hambre. Rosell aceptó, pero pidió que antes le entregaran cien pesetas para el proyecto de un Certamen Naturista, lo cual la Sociedad se negó a hacer. Anónimo, "Epistolario", en El Naturista, Carlet, año I, nº 5, p. 35. así fue que los adoptó y siguió de manera escrupulosa como modo de conducta. Sin embargo, consideraba que esos métodos no eran suficientes para resolver los enormes problemas que afectaban a la humanidad. Así lo explicitó en el Exordio que acompañó a la publicación de su conferencia, donde afirmaba que el naturismo "no es sólo Vegetarismo, Hidroterapia, etc., etc., ya que sólo acepta esas fracciones como medios, pues como finalidad reclama mucho más: La felicidad integral del Hombre sobre la Madre Tierra." 59 Según estimaba, el error de los médicos naturistas radicaba en que, absortos en interminables discusiones acerca de qué técnicas resultaban más efectivas para la cura de las distintas enfermedades, habían olvidado el horizonte al cual tendía el naturismo como proyecto social de reforma de los estilos de vida. Mientras se limitaran a estudiar los mecanismos terapéuticos de perfeccionamiento de la salud física, cabría entonces realizarles los mismos reproches que a los practicantes de la medicina oficial: su tarea terminaba restringiéndose al ejercicio de una filantropía que garantizaba a los dueños de las fábricas mayores sumas de ingresos a través del aumento de la productividad de los explotados. ${ }^{60}$

De esta manera, Rosell volvía contra los naturistas la crítica que estos mismos realizaban a los diplomados cuando les echaban en cara que sólo se preocupaban por el tratamiento de los efectos, desentendiéndo las verdaderas causas de la enfermedad. " $[L] \mathrm{o}$ que podemos llamar masa naturista no busca [...] una filosofía sino un alivio a males físicos, que pocas veces logra, merced al estado social indigno que nos envuelve, lo que evidencia la necesidad de la faz social, o mejor sociológica del Naturismo..." —escribió en El naturismo integral y el hombre libre. ${ }^{61} \mathrm{Si}$, junto al estudio de los métodos destinados a tratar las perturbaciones que afectaban al organismo, los naturistas no abordaban también las causas del desorden social, entonces su disciplina no dejaría de ser un apéndice, más o menos herético, de la medicina oficial.

A estas diferencias que Rosell manifestaba a propósito de quienes concebían el naturismo desde su aspecto exclusivamente terapéutico, se sumaba otro malestar aún mayor que encontraba como "criterio [...] dominante en las publicaciones naturistas destinadas a la masa". 62 Éste remitía a la tendencia, cada vez más arraigada, de hacer uso de los saberes y métodos naturistas de cura con fines comerciales. Arribistas, filisteos y curanderos fueron algunos de los epítetos que utilizó en alusión a los dueños de comercios de productos naturales y a quienes ofrecían sus servicios a cambio de dinero en clínicas y consultorios. A ellos

59 Albano Rosell, Aspecto médico-social..., op. cit., pp. VI-VII.

60 Ibídem, p. 17. Una crítica similar realizaba, desde las páginas de la revista cubana Pro-Vida, el anarco-naturista catalán Adrián del Valle, también conocido por su seudónimo Palmiro de Lidia. Eduard Masjuan Bracons, op. cit., p. 443. Sobre las relaciones entre anarquismo y naturismo en Cuba, Kirwin Shaffer, "Curing Bourgeois Ills. Anarcho-Naturism vs. Cuba's Medical Establishment", en Anarchist Cuba..., op. cit., pp. 126-143.

61 Albano Rosell, El Naturismo integral..., op. cit., p. 10.

62 Albano Rosell, Aspecto médico-social..., op. cit., p. 18. 
dedicó varias páginas de El naturismo integral y el hombre libre, y dos apartados enteros de su conferencia publicada con el título de Naturismo en acción. Su encono por el daño que producían al corromper el ideal de vida que él profesaba, lo llevó a expresar —en el primero de los textos referidos- que la sola enumeración de sus aberraciones "sería bastante para fusilarles por la espalda como naturistas, si no lo merecieran como analfabetos". 63

La explotación con fines comerciales de cierto furor que la novedad del naturismo había despertado entre algunos sectores de la sociedad a comienzos del siglo XX no era, sin embargo, exclusiva de España o Europa. Rosell encontraba que, penosamente, este desvío de lo que él consideraba como un proyecto genuino de regeneración física y moral también se había producido en el Río de la Plata. Los años durante los cuales residió en Montevideo dejaron en él una triste impresión acerca de la forma que había tomado en estas latitudes el desarrollo del naturismo. Ya en 1912, expresaba desde las páginas de la revista Infancia que "el naturismo, tal como está establecido y funciona entre nosotros, es un asqueroso negocio, un comercio sin entrañas, entrevero de ocultismos y sugestiones, de hipocresías y fanfarria". ${ }^{44}$ Seis años más tarde y desde el otro lado del Océano Atlántico, recordaría aquellas regiones como un "semillero de centros naturistas a base de negocio y especulación", en los que cualquier inescrupuloso "alquila un local, le pone una placa reluciente, hace circular voces de que curará enfermos, [...] inicia una lista de socios con cuotas mensuales, instala un servicio de baños, y hételo por obra y gracia de su 'sans façon', convertido en Profesor naturista". 65 Procurando tomar distancia de estas costumbres indignas que buscaban clientes entre personas desesperadas por recobrar la salud, Rosell elaborará su concepción de naturismo integral y hará propaganda por la adopción de un estilo de vida sencillo y frugal.

\subsection{El naturismo integral como proyecto de reforma}

De manera similar a su amigo Henry Zizly y otros anarcoindividualistas franceses practicantes del naturismo, Rosell atribuía la causa del malestar que padecía la humanidad al desarrollo de la civilización y su escisión de la naturaleza. El origen de estos males — sostenía - era tan antiguo como el pasaje del nomadismo al sedentarismo. ${ }^{66}$ Sin embargo, el cambio

63 Ibídem, p. 20.

64 Albano Rosell, "Astorga", en Infancia, Montevideo, Año I, n 7, julio de 1912, pp. XXVI-XXVII, p. XXVII. En este mismo artículo, Rosell anunció la pronta salida de un libro de su querido amigo Dr. Zeda con prólogo del reconocido Dr. Frank Aube, ambos seudónimos suyos.

65 Albano Rosell, Naturismo en acción, op. cit., p. 58.

66 Albano Rosell, El naturismo integral..., op. cit., p. 53; El Naturista, "Nuestra doctrina naturista", en El Naturista, año I, n 4, 15/03/1922, pp. en los hábitos de vida propiciados por los avances tecnológicos y la oferta de nuevos productos de consumo durante las primeras décadas del siglo $\mathrm{XX}$, le ofrecía argumentos para actualizar su crítica a los modos de organización social. Así, dirigía sus ataques contra el uso de la electricidad para la producción de luz artificial, del maquinismo y las formas tayloristas de producción en serie, del empleo de la química para la industria alimentaria y farmacéutica, de la difusión de medios de locomoción guiados por el afán de alcanzar cada vez mayores velocidades. En respuesta a estos procesos corruptores de un presunto estado originario de armonía y plenitud, hacía un llamado a desandar el camino de perversión que había llevado a la humanidad a su condición actual. De este modo, es posible encontrar, en varios de sus escritos, expresiones como aquella con la cual anunció el objeto al que estaría dedicada la revista que editó entre 1922 y 1923 desde la ciudad valenciana de Carlet: "Nuestro ideal es el Naturismo integral", y éste consiste en el "retorno a la Madre Tierra, estudio de sus sabias disposiciones y aprovechamiento de todas las cualidades bienhechoras de la especie", no obstante lo cual, se lamentaba una vez más, "no todos los que se adjetivan naturistas lo entienden así...".67

En su trabajo sobre la historia del naturismo en Francia, Arnaud Baubérot encuentra que, a fines del siglo XIX, las referencias anarquistas a los orígenes de la humanidad como un paraíso perdido remitían menos al deseo de retorno a un pasado inmemorial que a la esperanza en el surgimiento de un nuevo orden levantado sobre las ruinas del presente. Sin embargo, a medida que la violencia terrorista que sacudió al país galo en la primera mitad de la década de 1890 empezaba a ser un recuerdo cada vez más lejano, también comenzarían a quedar atrás las expresiones milenaristas que dotaban de sentido formas no violentas de ejercicio de la militancia individualista. ${ }^{68}$ Hacia comienzos del siglo XX, las concepciones sobre el estado de naturaleza que alimentaban las fantasías de los anarquistas practicantes del naturismo ya no se asociarían a la idea de una destrucción absoluta e intempestiva del orden social. El declive de las expectativas de que en el corto plazo se produzca una revolución que trastoque de manera radical y definitiva los modos de existencia arrojó a los individualistas tras la búsqueda de otras formas de practicar la militancia. La imagen del individuo llamado a clavar un puñal en la sociedad que lo oprime fue reemplazada por la del que, armado de paciencia, aspira a cambiar el mundo a través de una previa transformación de su propio estilo de vida. ${ }^{69}$

24-25.

67 La Redacción, "Nuestra obra", en El Naturista, Carlet, Año I, nº 1, p. 1.

68 Cabe al respecto señalar que la presencia de expresiones e imágenes cristianas en el discurso revolucionario no era exclusiva del anarquismo, sino que pertenecía a una larga tradición de distintas corrientes de izquierda. A propósito de esto, Joël Delhom, "Anarquismo y Biblia: una perspectiva genealógica", en Joël Delhom y Daniel Attala (dirs.), Cuando los anarquistas citaban la Biblia. Entre mesianismo y propaganda, Madrid, Libros de la Catarata, 2014, pp. 25-60.

69 Arnaud Baubérot, op. cit. Sobre el anarquismo individualista en España y 
Los escritos de Rosell nos hablan de este segundo modo de comprender y ejercer su actividad militante. Un modo muy distinto al rumbo que — según él mismo expresó- decidió tomar su amigo Mateo Morral, quien, "[i]mpaciente para tocar los resultados de su dedicación emancipadora en los otros, [...] no reparaba, en su afán bondadoso y de ilusión, que unos años son partícula insignificante en relación con el infinito".70 El proyecto de regeneración física y moral al que Rosell buscó dotar de un principio filosófico a través de su concepción de naturismo integral era un proyecto a largo plazo. Enlazado a su labor pedagógica, lo consideraba como un trabajo de reeducación que Llevaría varios años, si no generaciones enteras, y, por tanto, que debía comenzar en los primeros momentos de la infancia. En este mismo sentido, era un tanto escéptico de que los adultos pudieran modificar sus malos hábitos, condicionados por toda una vida de falsos progresos y sus respectivos efectos perniciosos sobre la salud y las conductas. Tal era el objeto de la ponencia que esperaba presentar en el Congreso de Lisboa, en cuya copia mecanografiada se lee que, debido a los criterios confusos por nociones quiméricas que nublan la vista de los adultos, es preciso tomar "como centro de acción de nuestra obra, la tarea ímproba, pero vital, de reformar, regenerar, naturalizar, educar a nuestros hijos, a la infancia toda". ${ }^{71}$

Antes que un conjunto de técnicas terapéuticas que puedan comenzar a ensayarse de un día para otro, el naturismo integral era, para Rosell, un proyecto general de reforma que, partiendo del individuo, tomaba por objeto a la sociedad en su conjunto. Un proyecto que -como refiere en el Exordio del Aspecto médicosocial de la dignidad humana - "abarca todos los aspectos de la vida, por eso es filosofía, todos los puntos necesarios a nuestra condición de seres racionales, de seres hijos de una madre común". ${ }^{72}$ Mientras tanto, en El naturismo integral y el hombre libre, volvía a diferenciarse de quienes, haciéndose llamar naturistas, "parten del principio de que el hombre es un ser esencialmente físico", descuidando el examen de su dimensión social y moral, emotiva e intelectual. ${ }^{73} \mathrm{Y}$ a propósito de estas últimas, enlazaba a las perspectivas médica, sociológica y pedagógica que integraban su apuesta transformadora, la preocupación por el estudio de las artes. En definitiva, una suerte de proyecto transdisciplinario de reforma individual y social de los estilos de vida.

En el texto escrito en 1905 para la entrada "Anarquismo" de La Enciclopedia Británica, Piotr Kropotkin comienza definiéndolo como "el nombre que se da a un principio o teoría de la vida y la conducta que concibe una sociedad sin gobierno". Luego,

su relación con el naturismo durante la II República, Diez, Xavier, "Naturismo y anarcosindicalismo", en El anarquismo individualista en España (1923-1938), Barcelona, Virus Editorial, 2007, pp. 304-317.

70 Antonio Roca, Vidas trágicas..., op. cit., p. 74.

71 Albano Rosell, Naturismo y educación..., op. cit., p. 6.

72 Albano Rosell, Aspecto médico-social..., op. cit., p, VI.

73 Albano Rosell, El naturismo integral..., op. cit., p. 66. algunas líneas más abajo, refiere que "[e]l progreso de la técnica moderna, que simplifica maravillosamente la producción de todos los elementos necesarios para la vida [...] [refuerza] firmemente la tendencia de no gobierno".74 Podríamos decir que, mientras el concepto de naturismo integral de Rosell acordaba con la primera de estas citas extraídas de la definición de Kropotkin, rechazaba de plano la segunda. De manera similar a otras experiencias históricas de militancia que adoptaron también prácticas naturistas del cuidado de la salud, para el catalán éstas cobraban sentido como parte de un proyecto ético con el cual avanzar hacia una nueva forma de vida. Y ésta no podía realizarse de manera acabada dentro del contexto de desarrollo tecnológico que había alcanzado la modernidad. Desde su perspectiva, los artefactos técnicos no eran herramientas cuya utilidad pudiera fácilmente reformularse según la manera en que se los emplee o el régimen de propiedad al que pertenezcan. El problema de los ferrocarriles, aviones o automóviles no era que estuviesen en manos privadas, sino que conjuraban contra esa misma simpleza que Kropotkin creía que permitirían alcanzar, contra "las delicias del caminar — afirmaba Rosell- que nos permite detenernos a contemplar las cosas bellas, los parajes gratos, descansar a su vera, emocionarnos, intimar con el nuevo panorama". ${ }^{75}$ De esta manera, el naturismo integral tomaba la forma de una reacción a los cambios en las conductas producidos por las novedades tecnológicas de la modernidad, frente a la cual Rosell hacía un llamado en favor de la adopción de una vida sencilla y frugal. Esta se alcanzaría a través de una reflexión minuciosa sobre los hábitos cotidianos de las personas, capaz de distinguir las necesidades de orden primario de los vicios, lujos y placeres superfluos. Entre éstos, incluía el consumo de alcohol, tabaco, carne y mate, la utilización de adornos y prendas que no tuvieran por objeto el solo resguardo del frío, las costumbres noctámbulas y los juegos de azar, los deportes de competencia y el arte dedicado al mero entretenimiento. ${ }^{76}$

En fin, la búsqueda de Rosell por hacer del naturismo integral una filosofía capaz de repensar de manera crítica cada ámbito de la vida, asemeja su proyecto a lo que Bronislaw Baczko denominó "el ejercicio intelectual del paradigma utópico". Se trata del intento de ofrecer una respuesta a la pregunta abierta por la modernidad acerca de la autoinstitución de lo social, y la posibilidad que de ella se desprende de imaginar modos de

74 Pedro Kropotkin, Folletos revolucionarios II. Ley y autoridad, Trad. de José Manuel Álvarez Flores y Ángela Pérez, Barcelona Tusquets, 1977, pp. 123 y 125

75 Albano Rosell, El naturismo integral..., op. cit., p. 45

76 Con respecto a la vestimenta, la crítica a sus malos hábitos - ya presente, como vimos, en Mary Gove Nichols, en referentes del naturismo como Sebastian Kneipp y en movimientos de reforma como la Lebensreform- fue uno de los factores que motivó en el naturismo libertario español el surgimiento de un movimiento nudista. Cfr. María Carmen Cubero Izquierdo, La pérdida del pudor. El naturismo libertario español (1900.1936), Madrid, LaMalatesta Editorial, 2015. 
existencia por completo alternativos a los existentes. ${ }^{77}$ Estas reflexiones conclusivas remiten a que el propio Rosell fue autor de una utopía titulada Una visita a Macrobia, publicada en 1921 con el seudónimo de Germina Alba y vuelta a publicar, siete años más tarde —cuando el autor se encontraba ya de regreso en Montevideo-, bajo su propio nombre y el título de En el país de Macrobia. ${ }^{78}$ La novela narra la historia de una mujer que recorre el mundo en busca de datos y costumbres que le permitan, como a Kropotkin, avanzar en la escritura de artículos para una enciclopedia. Tras encontrarse en Río de Janeiro con un viejo amigo, emprende junto con él un viaje a un país escondido en la selva amazónica, en el que, en resumidas cuentas, sus seis millones y medio de habitantes viven la vida que Rosell aseguraba poder alcanzar si la sociedad entera se prestara a seguir su proyecto de reforma. ${ }^{79}$ Volviendo al comienzo de este artículo, considero que, a la luz de su apuesta por un naturismo integral, la lectura de la utopía podría permitirnos comprender la fuerte preocupación que Rosell manifestaba por los modos de conducta ética como un intento de actualizar sus deseos de vida futura.

\section{Bibliografía}

\section{Fuentes documentales: libros y folletos}

Alba, Germina, Una visita a Macrobia (Notas para la narración todavía en bruto, titulada "En el país de Macrobia"), Barcelona, Biblioteca Educación y Revista Naturismo, 1921.

Claridge, Richard T., Hidropathia, o cura por medio del agua fría, según la práctica de Vicente Piressnitz, en Graefenberg, en Silesia, Austria, Buenos Aires, Imprenta Americana, 1850.

Gove Nichols, Mary, A Woman's Work in Water Cure and Sanitary Education, Londres, Nichols and Co., 1874.

Kneipp, Sebastian, Cómo habéis de vivir, Trad. de Francisco García Ayuso, Barcelona, Juan Gili, 1902.

—, Método de hidroterapia, Trad. de Francisco García Ayuso, Barcelona, Juan Gili, 1909.

77 Bronislaw Baczko, Los imaginarios sociales. Memorias y esperanzas colectivas, Trad. de Pablo Betesh, Buenos Aires, Nueva Visión, p. 68.

78 Germina Alba, Una visita a Macrobia (Notas para la narración todavía en bruto, titulada "En el país de Macrobia"), Barcelona, Biblioteca Educación y Revista Naturismo, 1921; Albano Rosell, En el país de Macrobia, Barcelona, Biblioteca Naturismo, 1928.

79 A sabiendas de que estas reflexiones finales ameritarían un mayor desarrollo que, por cuestiones de extensión, exceden a este artículo, remito a Adriana Petra, "La utopía del individuo integral o el mito de la Arcadia sudamericana. Anarquismo, eugenesia y naturismo en el Viaje al país de Macrobia", Políticas de la Memoria, n 5, 2004-2005, pp. 43-56.
Kropotkin, Pedro, Folletos revolucionarios II. Ley y autoridad, Trad. de José Manuel Álvarez Flores y Ángela Pérez, Barcelona Tusquets, 1977.

Kuhne, Louis, La nueva ciencia de curar o enseñanza de la unidad de las enfermedades y su curación sin medicamentes y sin operaciones, basada en ella, Trad. de J. O. Monsterios e I. López Lapuya, Decimoquinta edición española, s/d.

Metcalfe, Richard, Life of Vincent Priessnitz. Founder of Hidropathy, Londres, Simpkin, Marshall, Hamilton, Kent and Co., 1898.

Roca, Antonio, Vidas trágicas. Mateo Morral. Francisco Ferrer, Montevideo, copia mecanografiada, 1940.

Rosell, Albano, Naturismo y educación de la infancia, Valencia, copia mecanografiada, 1918.

- Aspecto médico-social de la dignidad humana, Barcelona, Instituto Naturista Hispano Americano, 1921.

—, Naturismo en acción, Barcelona, Instituto Naturista Hispano Americano, 1922

—, En el país de Macrobia, Barcelona, Biblioteca Naturismo, 1928.

-, Rasgos y anécdotas de algunas personas, Montevideo, copia mecanografiada, 1957.

—, El naturismo integral y el hombre libre, Montevideo, copia mecanografiada, s/f.

\section{Fuentes documentales: publicaciones periódicas}

El Naturista, Carlet, 1922-1923.

Ideas y figuras, Buenos Aires, 1910.

Infancia, Montevideo, 1912-1916.

La Protesta, Buenos Aires, años consultados: 1932-1933.

La Revista Blanca, Madrid, 1902.

Nuestra Tribuna, Necochea, 1923.

\section{Fuentes secundarias}

Agulló Díaz, María Carmen y Molina Beneyto, María Pilar, Antonia Maymón. Anarquista, maestra, naturista, Barcelona, Virus editorial, 2014.

Álvarez Junco, José, La ideología política del anarquismo español (1868-1910), Madrid, Siglo XXI de España Editores, 1976. 
Artetxe, Alejandro, Historia de la medicina naturista española, Madrid, Triacastela, 2000.

Baczko, Bronislaw, Los imaginarios sociales. Memorias y esperanzas colectivas, Trad. de Pablo Betesh, Buenos Aires, Nueva Visión.

Barrán, Juan Pedro, "Biología, medicina y eugenesia en Uruguay", en Asclepio, Vol. LI, n² 2, 1999, pp. 11-50.

Barrancos, Dora, Anarquismo, educación y costumbres en la Argentina de principios de siglo, Buenos Aires, Editorial Contrapunto, 1990.

Baubérot, Arnaud, Histoire du naturisme. Le mythe du retour à la nature, Rennes, Presses universitaires de Rennes, 2015.

Bivins, Roberta, Alternative Medicine? A History, Nueva York, Oxford University Press, 2007.

Blécourt, Willem de y Usborne, Cornerlie, "Situating 'Alternative Medicine' in the Modern Period", en Medical History, $n^{\circ} 43$, 1999, pp. 283-285.

Bradley, James, "Medicine on the margins? Hydropathy and orthodoxy in Britain, 1840-60", en Waltraud Ernst (ed.) Plural Medicine, Tradition and Modernity, 1800-2000, Nueva York, Routledge, 2002, pp. 19-39.

Bradley, James y Dupree, Marguerite, "A Shadow of Orthodoxy? An Epistemology of British Hydropathy, 1840-1858", en Medical History, $n^{\circ}$ 47, 2003, pp. 173-194.

Bynum, William F. y Porter, Roy (eds.), Medical Fringe and Medical Orthodoxy, 1750-1850, Londres y Wolfeboro, Croom Helm, 1987.

Cleminson, Richard, Anarquismo y sexualidad en España (19001939), Cádiz, Servicio de Publicaciones de la Universidad de Cádiz, 2008.

Cooter, Roger (ed.), Studies in the History of Alternative Medicine, Londres, Palgrave Macmillan, 1988.

Cubero Izquierdo, María Carmen, La pérdida del pudor. El naturismo libertario español (1900.1936), Madrid, LaMalatesta Editorial, 2015

Diez, Xavier, El anarquismo individualista en España (1923 1938), Barcelona, Virus Editorial, 2007.

Fernández de Mendiola, Francisco, Isaac Puente. El médico anarquista, Tafalla, Editorial Txalaparta, 2007.

Garay Montaner, Gerardo, "La discusión en torno a la implementación de la Escuela Integral en el marco de la propaganda racionalista en Montevideo, 1911-1916", en Revista Latino-Americana de Historia, Vol. 6, n 17, junio-julio de 2017, pp. 7-26.

—, "Anarquistas y racionalistas en el marco de la 'Liga Popular para la Educación Racional de la Infancia'. Montevideo, 1911-1916", en Avances del Cesor, Vol. XIV, № 17, julio-diciembre de 2017, pp. 39-61.

Harrison, J. F. C., "Early Victorian Radicals and the Medical Fringe", en William F. Bynum y Roy Porter (ed.), Medical Fringe and Medical Orthodoxy, 1750-1850, Londres y Wolfeboro, Croom Helm, 1987, pp. 198-215.

Kirchfeld, Friedhelm y Boyle, Wade, Nature Doctors. Pioneers in Naturopathic Medicine, Portland, NCNM Press, 1994.

Litvak, Lily, Musa libertaria. Arte, literatura y vida cultural del anarquismo español, Barcelona, Antoni Bosch, 1981.

Marland, Hilary y Adams, Jane, "Hydropathy at Home: The Water Cure and Domestic Healing in Mid-Nineteenth-Century Britain", en Bulletin of the History of Medicine, Vol. 83, n³, 2009, pp. 499-529.

Masjuan Bracons, Eduard, La ecología urbana en el anarquismo ibérico: urbanismo "orgánico" o ecológico, neomalthusianismo y naturismo social, Barcelona, Icaria, Madrid, Fundación de Estudios Anselmo Lorenzo, 2000.

Molero Mesa, Jorge y Jiménez Lucena, Isabel, "'Otra manera de ver las cosas'. Microbios, eugenesia y ambientalismo radical en el anarquismo español del siglo XX", en Marisa Miranda y Gustavo Vallejo (eds.), Darwinismo social y eugenesia. Derivas de Darwin: cultura y política en clave biológica, Buenos Aires, Siglo XXI, 2010, pp. 143-164

Navarro Navarro, Francisco Javier, "Anarquismo y Neomalthusianismo: la revista Generación Consciente (19231928)", en Arbor, Vol. CLVI, nº 615, marzo de 1997, pp. 9-32.

Navarro Navarro, Francisco Javier, "El paraíso de la razón". La revista Estudios (1928-1937) y el mundo cultural anarquista, Valencia, Edicions Alfons el Magnànim - IVEI, 1997.

Nieto-Galan, Agustí, Los públicos de la ciencia. Expertos y profanos a través de la historia, Madrid, Marcial Pons, 2011. 
Petra, Adriana, "La utopía del individuo integral o el mito de la Arcadia sudamericana. Anarquismo, eugenesia y naturismo en el Viaje al país de Macrobia", en Políticas de la Memoria, $n^{\circ} 5$, 2004-2005, pp. 43-56.

Porter, Roy, "Before the Fringe: 'Quackery' and the EighteenthCentury Medical Market", en Roger Cooter (ed.), Studies in the History of Alternative Medicine, Londres, Palgrave Macmillan, 1988, pp. 1-27.

- (ed.), The Medical History of Waters and Spas. Medical History, Supplement $n^{\circ} \mathbf{1 0}$, Londres, Welcome Institute for the History of Medicine, 1990.

Ramsey, Matthew, "Alternative Medicine in Modern France", Medical History, n 43, 1999, pp. 286-322, pp. 289-290.

Rodríguez-Sánchez, Juan A., "Una alternativa restringida: la introducción de la hidropatía en España", en Elvira Arquiola y José Martínez-Pérez (eds.), Ciencia en expansión: estudios sobre la difusión de las ideas científicas y médicas en España (siglos XVIII-XX), Madrid, Editorial Complutense, 1995, pp. 322-349.

—, "Moralismo higiénico: la terapéutica del abate Kneipp y su introducción en España", en Luis Montiel e Isabel Porras (coords.), De la responsabilidad individual a la culpabilización de la víctima. El papel del paciente en la prevención de la enfermedad, Aranjuez, Doce Calles, 1997, pp. 33-54.

Roselló, Josep, La vuelta a la naturaleza. El pensamiento naturista hispano (1890-2000): naturismo libertario, trofología, vegetarismo naturista, vegetarismo social y librecultura, Barcelona, Virus Editorial, 2003.

Scriven, Tom, Popular virtue. Continuity and change in Radical moral politics, 1820-70, Manchester, Manchester University Press, 2017.

Shaffer, Kirwin, Anarchist Cuba: Countercultural Politics in the Early Twentieth Century, Oakland, PM Press, 2019.

Solà i Gussinyer, Pere, Ferrer Guardia pedagogo y hombre de acción. La mirada apasionada de Alban Rosell sobre el fundador de la Escuela Moderna, Clavell, Gobierno de España, Ministerio de Cultura, 2011.

Stavisky, Sebastián, "Médicos de sí mismos. Medicina naturista, revolución social y éxodo de la ciudad en el anarquismo de Buenos Aires a comienzos del siglo XX", en Ecopolítica, $n^{\circ} 16$, 2016, pp. 2-25.

-, "Manuel Costa-Iscar y el anarquismo individualista en Buenos Aires", en Izquierdas, n 49, julio 2020, pp. 996-1017.
Vigarello, Georges, Lo limpio y lo sano. La higiene del cuerpo desde la Edad Media, Madrid, Alianza Editorial, 1991.

Whorton, James C., Nature Cures. The History of Alternative Medicine in America, Nueva York, Oxford University Press, 2002.

\section{Resumen}

El artículo busca dar cuenta de algunos de los elementos que permitan comprender las relaciones de tensión, debate y afinidad producidas hacia inicios del siglo XX entre el anarquismo y el naturismo. Para ello, se traza una breve historia de la medicina naturista que permita observar algunas de las distintas formas en que la misma fue practicada y difundida en Europa entre mediados del siglo XIX y comienzos del XX. Luego, a partir de un análisis documental de los escritos de Albano Rosell, uno de los militantes anarquistas que en España y el Río de la Plata dedicó mayores esfuerzos a difundir el naturismo, se analiza el modo en que lo comprendió como un proyecto de reforma individual y social de los estilos de vida. Se examinan sus críticas al ejercicio exclusivamente terapéutico y a la explotación con fines comerciales de la medicina naturista. Finalmente, se revisan algunos de los puntos centrales de su concepción de naturismo integral.

Palabras clave: Anarquismo; Estilos de vida; Medicina; Naturismo

\section{Abstract}

The article seeks to account for some of the elements that make it possible to understand the relations of tension, debate and affinity produced towards the beginning of the 20th century between anarchism and naturism. For this, it traces a brief history of naturopathic medicine in order to observe some of the different ways in which it was practiced and promoted in Europe between the mid-19th century and the beginning of the 20th. Then, from a documentary analysis of the writings of Albano Rosell, one of the anarchists who, both in Spain and the Río de la Plata, dedicated greater efforts to spread naturism, it studies the way in which he understood it as a project of reform of individual and social lifestyles. To do this, it examines his criticisms to the exclusively therapeutic exercise and commercial exploitation of naturopathic medicine. Finally, it reviews some of the central points of his conception of integral naturism.

Keywords: Anarchism; Lifestyles; Medicine; Naturism

Recibido: $15 / 05 / 2020$

Aceptado: 29/07/2020 


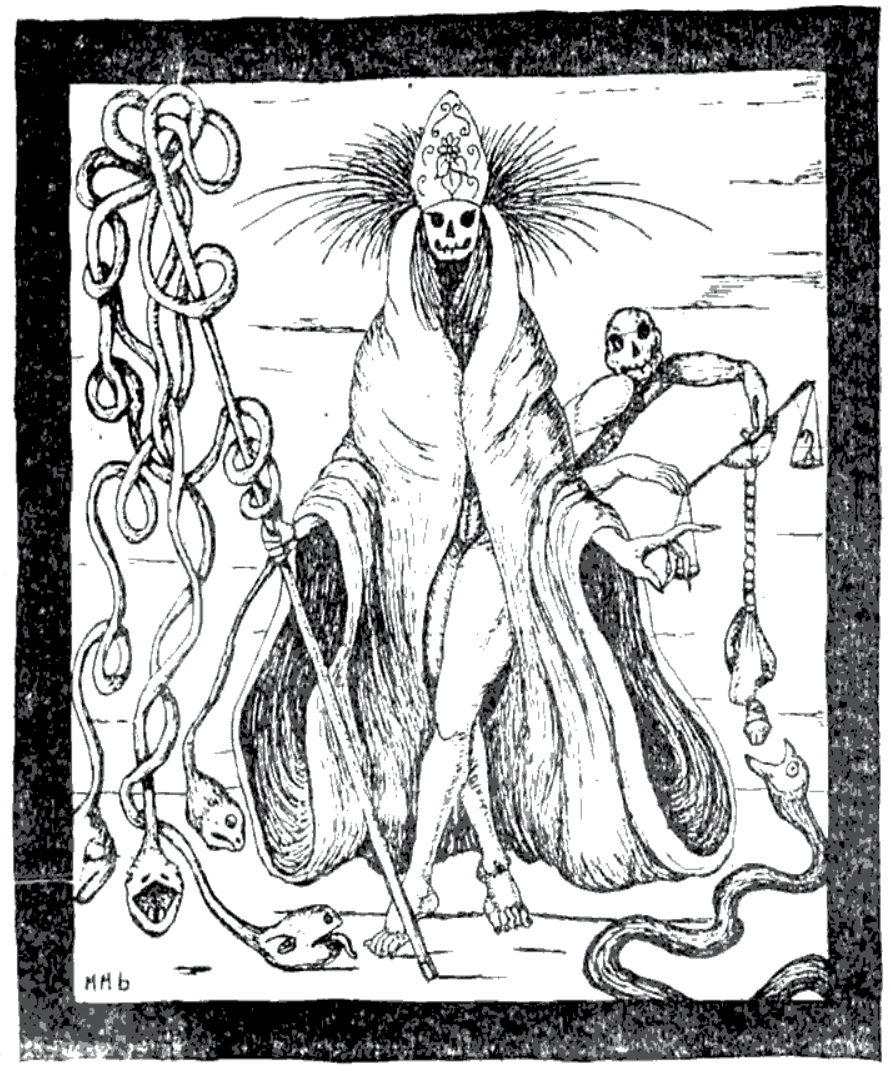

Ilustración de Marcelo Manuel Benítez en: Postdata,

a. 1, n² 2 (10/1984), p. 20. 